\title{
Cell response in rabbits infected with $T$. pallidum as measured by the Leucocyte Migration Inhibition Test
}

\author{
VICTORIA WICHER AND KONRAD WICHER \\ From the Erie County Laboratory, Division of Clinical Microbiology, and the Department of Microbiology, School \\ of Medicine, SUNY, Buffalo, New York
}

The immune response in the primary or secondary stage of syphilis in man is not as puzzling as that seen in the tertiary stage. Gummata or Clutton's joints or interstitial keratitis exemplify a possible association with cell-mediated immunity. Suggestive evidence for a hypersensitivity reaction in syphilis can be found in the reports of Turner (1936), Magnuson, Thomas, Olansky, Kaplan, De Mello, and Cutler (1953), and Csonka (1955), not to mention older reports. Since 1965 several European investigators have been using the in vitro lymphocyte transformation test to examine the leucocyte response to treponemal or cardiolipin reagents. Transformation of lymphocytes in vitro was found in all stages of syphilis. In the majority of cases positive results were found to correspond with the presence of treponemal antibodies. This topic was extensively reviewed by Sapupo and Lazzaro (1969).

Recently, Fulford and Brostoff (1972) studied leucocyte migration in the presence of Reiter antigen in patients at various stages of syphilis. They observed stimulation of leucocyte migration in patients with primary syphilis and inhibition of migration in late active syphilis; in secondary syphilis neither stimulation nor inhibition was seen. In the present report, leucocyte migration in agarose was used to examine the cell response of rabbits infected with Nichols strain of T. pallidum for various lengths of time. The leucocyte response was compared to that of the humoral.

\section{Material and methods}

\section{ANIMALS}

48 New Zealand rabbits (3-4 kg. each) infected intratesticularly at various times with approximately $2 \times 10^{7}$

Received for publication October 23, 1974

Supported by grant A1-11102-01 from the National Institute of Health, United States Public Health Service

Address for reprints: Dr. K. Wicher, Erie County Laboratory, Division of Clinical Microbiology, E. J. Meyer Memorial Hospital, 462 Grider Street, Buffalo, N.Y. 14215, U.S.A. organisms of $T$. pallidum Nichols strain and 26 noninfected rabbits were used for these experiments. The time of infection varied from 1 week to 16 months. The animals were examined:

(a) for the presence of lesions;

(b) for the cellular response;

(c) for the production of antibodies.

\section{ANTIGENS}

$T$. pallidum antigen ( $\mathrm{TpAg}$ ) was prepared in our laboratory. Organisms extracted from thirty infected rabbit testicles (orchitis) were separated from the tissue debris and extensively washed in saline containing azide $(1: 10,000)$. The treponemal suspension was submitted to 80 cycles of freezing $\left(-60^{\circ} \mathrm{C}\right)$ and thawing $\left(+37^{\circ} \mathrm{C}\right)$ and subsequently sonicated at $20 \mathrm{Kc}$ for 10 cycles, $2 \mathrm{~min}$. each (Sonifer Cell Disruptor, Model W140, Plainview, N.Y.). The material was centrifuged at 15,000 r.p.m. for $30 \mathrm{~min}$., and the supernatant examined for protein concentration (Lowry, Rosebrough, Farr, and Randall, 1951). The antigenic activity was examined in a complement-fixation test using known positive control human sera. The Reiter antigen (RAg) was a commercial product (Sylvana Company, Millburn, N.J.) prepared, according to the company's information, by the method of D'Alessandro modified by Cannefax and Garson (1957). This reagent was examined for protein concentration and activity in the complement-fixation test in a similar way to the TpAg. Before the protein determination both antigens were dialysed against phosphate buffered saline $\mathrm{pH} 7 \cdot 2$ to eliminate preservative, and subsequently against tissue culture TC199 (Grand Island Biological Company, Grand Island, N.Y.). Aliquots were stored at $-60^{\circ} \mathrm{C}$ until used. The Venereal Disease Research Laboratory (VDRL) reagent (lot No. 40764) was a commercial product of Bioquest (BBL, Cockeysville, Maryland.) Before each experiment this reagent was emulsified and diluted in TC 199.

\section{LEUCOCYTE MIGRATION INHIBITION IN AGAROSE PLATES}

The method of Clausen (1971) was used with some modifications. Peripheral blood was collected into a syringe containing 20 units preservative-free heparin (Abbott Laboratories, North Chicago, Ill.) per ml. blood. The heparinized blood was then mixed with 6 per cent. Dextran $500 \mathrm{~T}$ in saline (Pharmacia Fine Chemicals, 
Piscataway, N.J.) in a ratio of four parts of blood to one part of Dextran. After sedmentation of the erythrocytes, the leucocyte-rich plasma was centrifuged at $220 \mathrm{G}$ for $10 \mathrm{~min}$. and the leucocytes washed twice with Hanks's balanced salt solution (Grand Island Biological Company). The cells were subsequently suspended in TC 199 containing 20 per cent. inactivated horse serum, 50 $\mathrm{u} . / \mathrm{ml}$. penicillin and $50 \mu \mathrm{g} . / \mathrm{ml}$. streptomycin. The cell suspension was adjusted to $3 \times 10^{8} / \mathrm{ml}$. and $50 \mu \mathrm{l}$. of this suspension was mixed with $50 \mu$ l. of the chosen concentration of antigen and also $50 \mu \mathrm{l}$. TC 199 as a control. Alcohol diluted with TC 199 to a concentration similar to that of the VDRL reagent was used as an additional control. The mixture was incubated for $30 \mathrm{~min}$. at $37^{\circ} \mathrm{C}$ in a 5 per cent. $\mathrm{CO}_{2}$ atmosphere. The plates were prepared as follows: to each $10 \mathrm{ml}$. of 2 per cent, autoclaved hot agarose, $5.88 \mathrm{ml}$. sterile distilled water, $2 \mathrm{ml}$. TC 199 $(10 \times$ strength contining $500 \mathrm{u} . / \mathrm{ml}$. penicillin and 500 $\mu \mathrm{g} . / \mathrm{ml}$. streptomycin), $2 \mathrm{ml}$. inactivated horse serum and $0.12 \mathrm{ml}$. 6.5 per cent. sodium bicrabonate solution were added. $6 \mathrm{ml}$. of this mixture were poured into a $5 \mathrm{~cm}$. disposable plastic Petri dish (Falcon Division Becton Dickinson and Company, Oxnard, Ca.) and allowed to harden. Nine to twelve holes $2.3 \mathrm{~mm}$. in diameter were cut in the medium.

Ten $\mu l$. of the cell-antigen mixture were put into each well. Each sample was examined in triplicate and in each plate controls were included.

The plates were incubated for $18 \mathrm{hrs}$ in 5 per cent. $\mathrm{CO}_{2}$ at $37^{\circ} \mathrm{C}$. Two diameters of the migration zone were measured, the area calculated, and the results expressed as the migration index (MI), which represents the ratio of the average area of migration of leucocytes in the presence of antigen to the average area of migration of leucocytes in absence of antigen. The results were analyzed statistically using the unpaired $T$ test.

\section{SKIN TESTS}

Heat-killed $T$. pallidum in concentration of $5 \times 10^{7}$ in $0.2 \mathrm{ml}$. were injected intradermally into the back of each animal (Csonka, 1955). The reaction was read after $30 \mathrm{~min}$., and 4, 24, and $48 \mathrm{hrs}$.

\section{ANTIBODIES}

Sera were examined for the presence of antibodies by the VDRL slide flocculation test (Harris, Rosenberg, and Del Vecchio, 1948) and the FTA-ABS test (Hunter, Deacon, and Meyer, 1964). For the latter, goat antirabbit $\gamma$-globulin labelled with fluorescein isothiocyanate was prepared in our laboratory.

\section{Results}

\section{Course of infection}

All infected rabbits developed orchitis between 9 and 14 days after infection, which subsided within 1 week. Some rabbits subsequently developed syphilomas varying in size from 1 to $4 \mathrm{~cm}$. in diameter. None of the infected animals developed dark-field positive lesions on the distal parts of the body.

\section{Cell response}

Three different concentrations of the TpAg, RAg, and VDRL reagents were examined for a dose response using leucocytes of six normal adult New Zealand rabbits (purchased from the same source as the infected animals). The results are presented (Fig. 1) as the individual and the group mean values. The mean migration index (MI) of the leucocytes exposed to $6 \mu \mathrm{g} . / \mathrm{ml}$. RAg (0.97) is the closest to the MI of 1.0 , and this concentration was chosen for further experiments. The two higher concentrations of $\mathrm{RAg}-30$ and $150 \mu \mathrm{g} . / \mathrm{ml}$.-gave slightly lower mean MI values $(0.88,0.90)$. The $\mathrm{TpAg}$ examined in concentrations from 3 to $75 \mu \mathrm{g} . / \mathrm{ml}$. gave the best response with 3 and $15 \mu \mathrm{g} . / \mathrm{ml}$. (MI $=0.96,0.95)$,
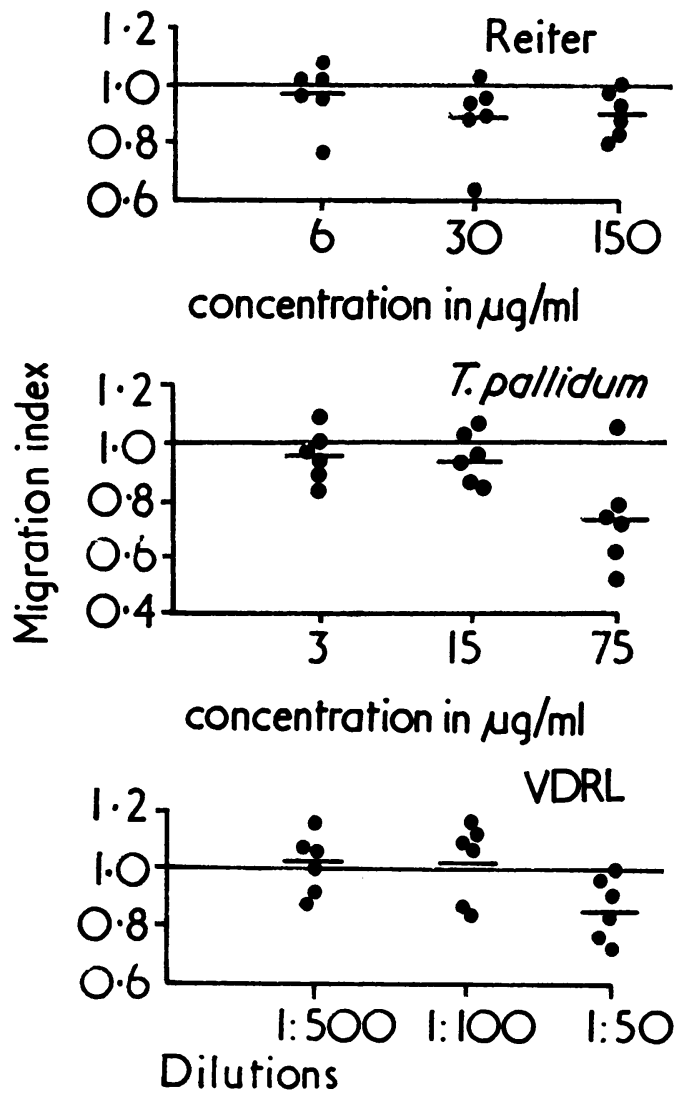

FIG. 1 Dose response of leucocytes of six normal rabbits to Reiter, T. pallidum, and VDRL antigens. Short bars indicate group mean value. Concentrations chosen for further experiments were:

Reiter antigen $-6 \mu \mathrm{g} . / \mathrm{ml}$., mean $M I=0.97$;

T. pallidum-3 $\mu \mathrm{g} . / \mathrm{ml}$., mean $M I=0.96$, and $15 \mu \mathrm{g} . / \mathrm{ml}$., mean $M I=0.95$;

$V D R L$ reagent in $1: 500$ dilution, mean $M I=1.02$. 
and these two concentrations were chosen for further experiments. The mean MI for the highest concentration of $\mathrm{TpAg}$ was $0 \cdot 76$. The VDRL antigen in dilutions of $1: 100$ and $1: 500$ gave identical mean $\mathrm{MI}$ values $(1.02)$ and, because the latter dilution contains less alcohol, it was chosen for further experiments.

The results of the cellular responses of the 48 infected rabbits are presented (Fig. 2) as ranges and group mean values of the MI. Normal rabbits were included in each experiment as a control for the stability of the antigens, especially the $\mathrm{TpAg}$; altogether twenty non-infected animals were used. The mean values obtained with the twenty control animals were very similar to those obtained with the six normal rabbits used for the dose response. The infected animals were grouped according to the postinfection time which ranged from 1 week to 16 months. The leucocyte response to $\mathrm{RAg}(6 \mu \mathrm{g} . / \mathrm{ml}$ ) showed a stimulation of migration during the first few weeks of infection, being significant $(P<0.01)$ at the second week. Inhibition of leucocyte migration followed the stimulation phenomenon, being significant $(P<0.05)$ at 6 months after infection. It is likely that the inhibition of migration appears much sooner, but this antigen was not used at 3 months after infection. The pattern of response of cells to the VDRL antigen was somewhat similar to that of $\mathrm{RAg}$-first, stimulation of migration (at 2 weeks $P<0.01$ ) merging later into the zone of inhibition of migration. However, the dilution of $1: 500$ of VDRL reagent never produced a significant inhibitory effect. The response to the $\mathrm{TpAg}$ at a concentration of $15 \mu \mathrm{g}$. $/ \mathrm{ml}$. was different. Inhibition of migration was noticed from the first week of infection, reaching a significant value at the 2nd week ( $P<0.01)$. These results were compared with those obtained using the lower concentration $(3 \mu \mathrm{g} . / \mathrm{ml}$.) of $\mathrm{TpAg}$ simultaneously. The results are illustrated in Fig. 3. 23 rabbits were examined. The cells of animals of the first three groups infected for 1 to 4 weeks responded to the

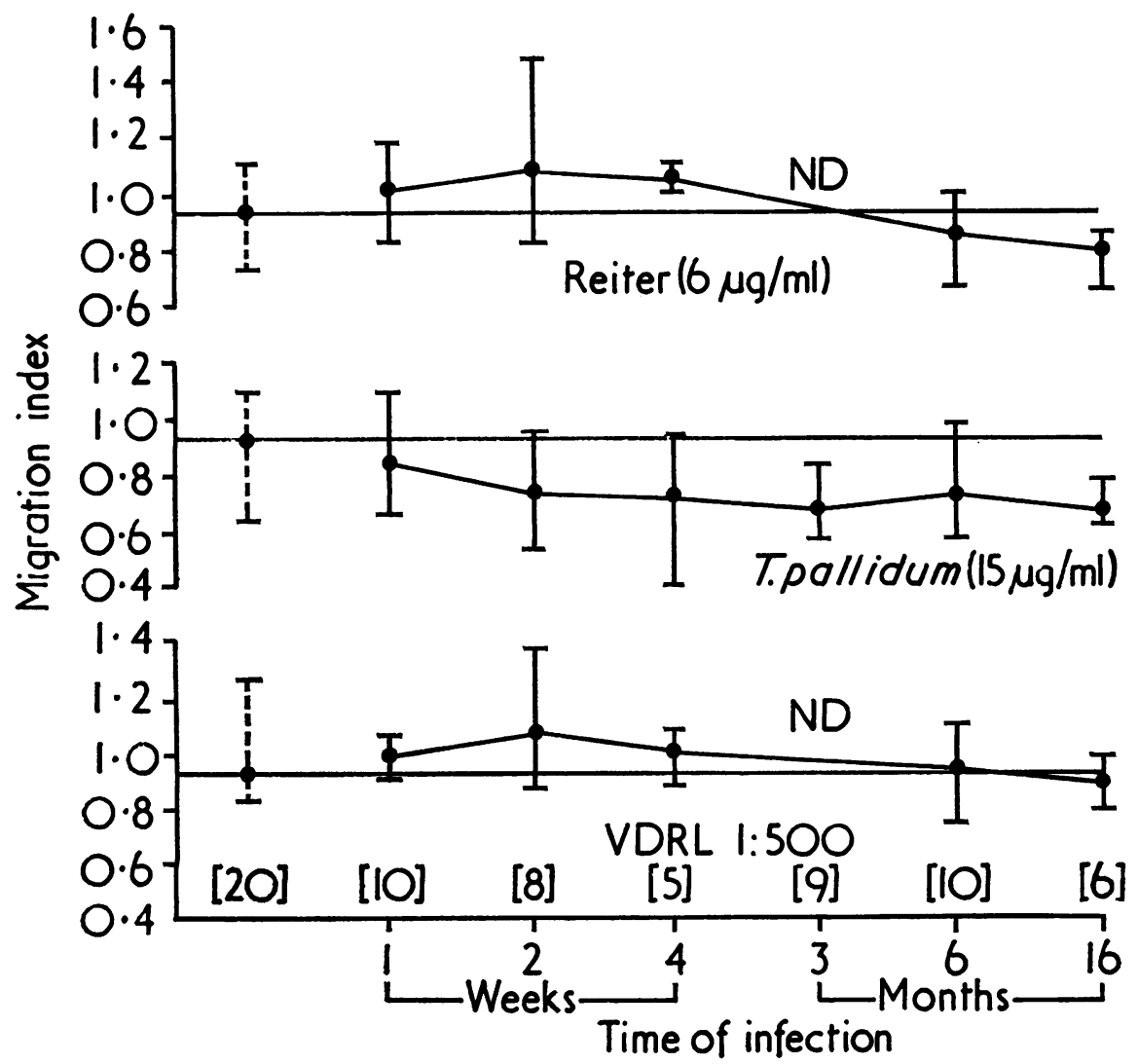

FIG. 2 Response of leucocytes of infected (solid lines) and non-infected rabbits (interrupted lines). Long horizontal line indicates mean value of control animals. Mean MI for all three antigens $=0.94$. Vertical lines represent ranges and solid dots mean values of groups. Number of rabbits used in each group shown in brackets. Biphasic responses may be observed with Reiter and VDRL reagents, whereas with $\mathrm{T}$. pallidum (15 $\mu \mathrm{g} . / \mathrm{ml}$.) only inhibition is seen. 


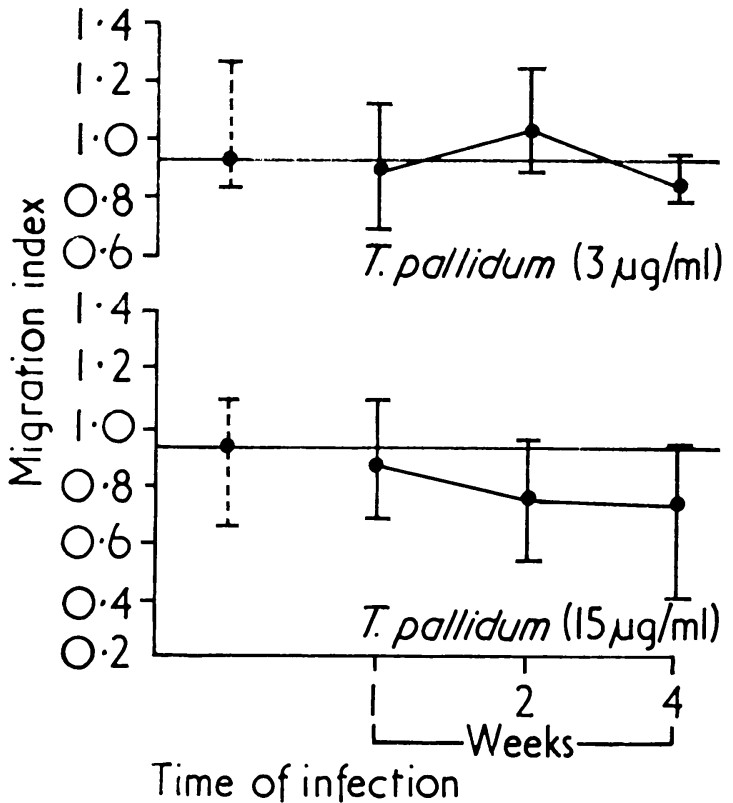

FIG. 3 Response of leucocytes of infected (solid line) and non-infected rabbits (interrupted line) to two concentrations of $\mathrm{T}$. pallidum antigen. (For description see Fig. 2.) Leucocytes of infected animals responded to lower concentration of antigen $(3 \mathrm{~kg} . / \mathrm{ml}$.) with migration stimulation, and to higher concentration (15: $\mathrm{kg} . / \mathrm{ml}$.) with migration inhibition. lower concentration of $\mathrm{TpAg}$ in a similar way to the RAg or VDRL antigen, first with stimulation of migration reaching the highest value at 2 weeks after infection and then through a period of 'normal response' into a period of leucocyte migration inhibition. The inhibition in the presence of $3 \mathrm{\mu g} . / \mathrm{ml}$. TpAg was significant $(\mathrm{P}-0.05)$ at 4 weeks after infection.

Skin tests

To confirm the cell response in vitro, skin tests were performed on 23 of these animals infected from 3 to 16 months and on eight normal rabbits. No immediate (30 min.), late $(4 \mathrm{hrs})$, or delayed hypersensitivity (24 to $48 \mathrm{hrs}$ ) reactions to the heat-killed $T$. pallidum were observed.

Antibodies

The Wassermann antibodies reacting with the VDRL antigen started to appear after 2 weeks of infection, reaching a maximum titre at 4 weeks. The antitreponemal antibodies first appeared at a similar time, but the maximum titre was not observed until 3 months of infection. The titre and time of appearance of the antitreponemal antibodies, expressed as the mean value for the whole group, was compared to the cellular response using $15 \mathrm{\mu g}$. $/ \mathrm{ml}$. TpAg (Fig. 4). At 3 months of infection the mean maximum titre of antitreponemal antibodies $(3,960)$ and the lowest value of the mean leucocyte migration index $(0 \cdot 71)$ were noted. Statistical analysis using Spearman rank order correlation revealed a coefficient of 0.6 and

$\square$ FTA-Abs.

Leucocyte migration

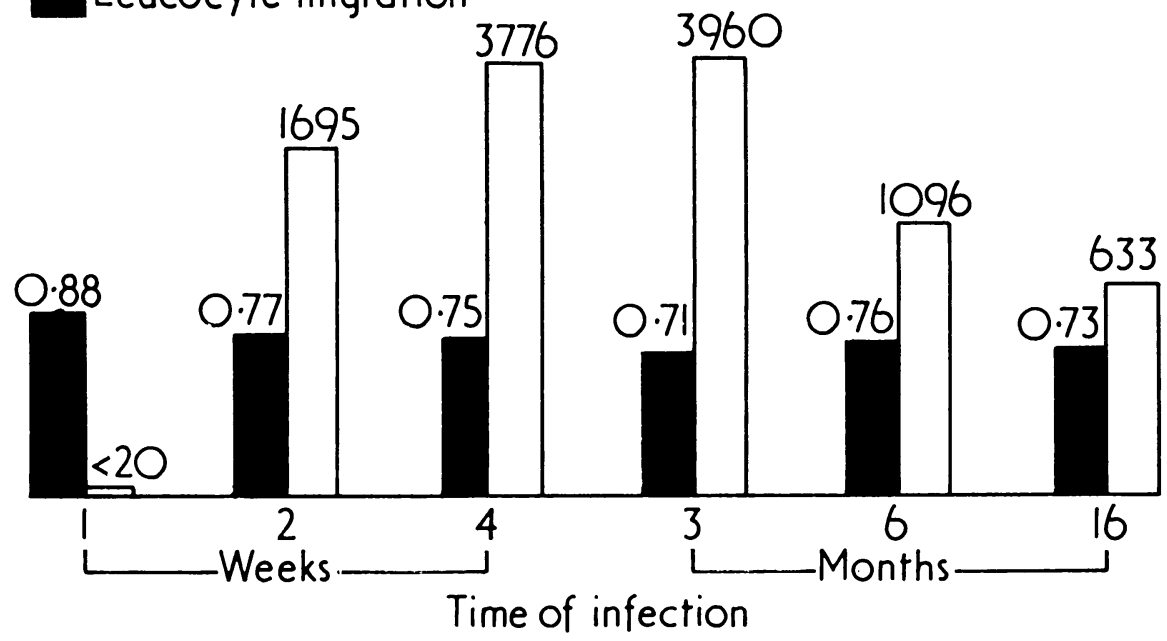

FIG. 4 Comparison of cellular response (solid bars) and humoral response (open bars). In general, no correlation between the cellular and humoral response was found. At 3 months of infection the lowest mean
MI (0.71) and the highest mean antitreponemal antibody titre (3960) were observed, but the correlation was not significant $\left(\begin{array}{lll}P & 0.05\end{array}\right)$. 
$P>0.05$, indicating for the six groups of animals a non-significant correlation between antibody production and leucocyte response.

\section{Discussion}

Although the course of syphilis in experimental animals cannot be compared to that in man, much basic information can be extracted from an animal model, information which may be useful in examining the cell response in man. The data presented suggest that leucocytes of rabbits infected with Nichols strain of $T$. pallidum in the presence of specific or crossreacting antigens release factor(s) stimulating or inhibiting leucocyte migration. The VDRL reagent in a dilution of 1:500 failed to cause significant leucocyte migration inhibition.

A phenomenon previously observed by Fulford and Brostoff (1972) was confirmed; namely, that in the early stage of an infection with $T$. pallidum, stimulation of migration takes place. Under our conditions it appeared in the presence of $6 \mu \mathrm{g} . / \mathrm{ml}$. $\mathrm{RAg}$, of $3 \mu \mathrm{g} . / \mathrm{ml}$. TpAg, and of VDRL reagent in 1: 500 dilution. $\mathrm{TpAg}$ in concentration of $15 \mu \mathrm{g} . / \mathrm{ml}$. caused only inhibition. Both the stimulation and inhibition of leucocyte migration can most likely be considered as a response of the activated cells to the specific or cross-reacting antigens. The question arises whether one or two types of cells are involved in the response, whether two factors are produced, as suggested by Fulford and Brostoff (1972), or whether the phenomenon is due to the correlation between the degree of sensitivity of the cells and the concentration of the antigen(s) used, as proposed by Søborg (1968). Our findings tend to support Søborg's hypothesis that low concentrations of antigen may stimulate leucocyte migration, assuming that the cells have a low to moderate degree of sensitivity. Cells with a high degree of sensitivity would produce, in the presence of low concentrations of antigen, a leucocyte migration inhibitory factor. High concentration of antigen(s), regardless of the degree of sensitivity (low or high) of the cells, would cause a leucocyte migration inhibition.

Using the $\mathrm{TpAg}$ in concentrations of 3 and $15 \mu \mathrm{g} . / \mathrm{ml}$., we have observed that the same cells at the same time, when exposed to the lower concentration, demonstrated stimulation of migration and, with the higher concentration, inhibition of migration (Fig. 3). Unfortunately, we did not attempt to confirm this phenomenon with the cross-reacting RAg and at this point we cannot answer the question whether the specificity of the antigen plays a role in the biphasic response. The VDRL antigen in dilution of 1:500 caused leucocyte stimulation but no significant inhibition. It is possible that the concentration used was too low to cause inhibition and that higher concentrations of the VDRL antigen could also produce a biphasic response. In a pilot experiment, cells of rabbits infected for $\mathbf{4 0}$ days, when challenged with VDRL antigen in 1:150 dilution, demonstrated inhibition of migration. This phenomenon, however, needs to be confirmed on a larger experimental material. Should this be the case then we should have to accept that the VDRL reagent, containing cardiolipin, lecithin, and cholesterol reacts as an antigen. We would have to take into consideration that the horse serum present in the tissue culture could play the role of a carrier. Cardiolipin as a hapten, according to the widely accepted view, could not-without the help of a protein carrier-elicit a cell response. The role and contribution of an immunogenic carrier in the specificity of a delayed hypersensitivity reaction has been well demonstrated (Paul, Katz, Goild, and Benacerraf, 1970; Schlossman and Yaron, 1970; Benacerraf and Gell, 1959; Benacerraf and Levine, 1962; David, Lawrence, and Thomas, 1964). Since controls using only cardiolipin were not included in our experiments, this problem remains to be explored.

In the experimental conditions described, cell response, as measured by leucocyte migration stimulation or inhibition, is demonstrated as early as the second week of infection and remains, at least in some rabbits, for more than 16 months after infection. However, the cellular response could not be correlated with any delayed hypersensitivity measured by skin tests using $5 \times 10^{7}$ killed $T$. pallidum in $0.2 \mathrm{ml}$. Similar dissociation of responses in other experimental or clinical models have been observed (Chilgren, Quie, Meuwissen, and Hong, 1967; Chilgren, Meuwissen, Quie, Good, and Hong, 1969; Kirkpatrick, Chandler, and Schimke, 1970). For the time being, we cannot offer any experimentally supported explanation for the dissociation phenomenon. We may speculate that the lack of delayed skin hypersensitivity may be due to several factors:

(1) The rabbit is not a counterpart model for the human in relation to the course of syphilis. The different stages of syphilis in rabbits are not well defined and do not correspond to the clinical findings observed in man.

(2) The rabbit, as is generally known, has a very low degree of cell sensitivity to various antigens or mitogens. In our experience, when eight normal and fourteen infected rabbits and eight normal guineapigs were examined for their susceptibility to PHA by skin tests with 2 and $10 \mu \mathrm{g}$. PHA, all guinea-pigs reacted with induration to $2 \mu \mathrm{g}$. PHA and only three infected rabbits developed induration after $10 \mu \mathrm{g}$. PHA. The difference in the response in vivo was confirmed by the response in vitro of lymphocytes to PHA. Bonforte, Topilsky, Siltzbach, and Glade (1972) reported a delayed skin reaction to $2 \mu \mathrm{g}$. PHA in apparently healthy individuals, including premature infants. Two guinea-pigs examined by these authors also reacted to $2 \mu \mathrm{g}$. PHA. 
(3) Insufficient dosage of killed $T$. pallidum used may be one of the several explanations. Király (1973) reported that $2 \times 10^{8}$ treponemes are needed for a positive skin test in man.

(4) Serum factor(s) inhibiting the skin reaction in vivo may be of basic importance in these consideraions. A serum factor inhibiting the cell response to PHA in vitro has been observed in patients with primary and secondary syphilis (Levene, Turk, Wright, and Grimble, 1969).

(5) The factors responsible in syphilitic rabbits for leucocyte migration stimulation or inhibition may be the product of other than T-cells, recognized so far as the putative effector of cell-mediated immunity. It is relevant here to stress the findings of Yoshida, Sonozaki, and Cohen (1973), who demonstrated the production in vitro of a macrophage inhibitory factor from isolated B cells using PPD and lipopolysaccharide.

There was no correlation between the cell response (leucocyte migration inhibition) and the treponemal antibodies, indicating that the two responses, humoral and cellular, are unrelated in the rabbit.

Similar observations in other experimental models have been reported (David, 1966; Søborg, 1967; Curtis and Hersh, 1973). In spite of the fact that the rabbit is not the best animal model to study cellmediated immunity in the course of infection with $T$. pallidum, basic information could be extracted from the experiments described. Since the rabbit is a susceptible and suitable animal for $T$. pallidum infection, further experiments involving cell response in this animal would be worthwhile to clarify the role of $T$-cells in the course of experimental infection with $T$. pallidum. Alternatively a better animal model for cell response should be used, e.g. the guinea-pig. This animal, however, is not a suitable model for experimental syphilis. The monkey will, most likely, be the best choice.

\section{Summary}

Leucocyte migration in agarose was used to examine cell response in 48 rabbits infected with the Nichols strain of $T$. pallidum for 1 week to 16 months. The response of the peripheral leucocytes to $T$. pallidum antigen ( $\mathrm{TpAg}$ ), 3 and $15 \mu \mathrm{g} . / \mathrm{ml}$., Reiter antigen (RAg) $6 \mu \mathrm{g} . / \mathrm{ml}$., and VDRL reagent $1: 500$ was examined. The cells in the presence of $\mathrm{RAg}, \mathrm{TpAg}-$ $3 \mu \mathrm{g} . / \mathrm{ml}$. - and the VDRL reagent demonstrated a biphasic response; in the early stage of infection (until the 4th week) stimulation of leucocyte migration and in the later stage of disease inhibition of leucocyte migration was observed. The higher concentration of $\mathrm{TpAg}-15 \mu \mathrm{g} . / \mathrm{ml}$. - caused only inhibition of leucocyte migration. The leucocyte response in vitro could not be confirmed by intradermal skin tests with $5 \times 10^{7}$ heat-killed $T$. pallidum. No correlation between the cell response and the treponemal antibodies was observed.

\section{References}

BeNACERRAF, B., and GeLI, P. G. H. (1959) Immunology, 2, 53

- and Levine, B. B. (1962) f. exp. Med., 115, 1023

BONFORTE, R. J., TOPILSKY, M., SIltZBaCH, L. E., and GLADE, P. R. (1972) f. Pediat., 81, 775

Cannefax, G., and Garson, W. (1957) Publ. Hlth Rep. (Wash.), 72, 335

Chilgren, R. A., Meuwissen, H. J., Quie, P. G., Good, R. A., and HoNG, R. (1969) Lancet, 1, 1286

, Quie, P. G., Meuwissen, H. J., and Hong, R. (1967) Ibid, 2, 688

Clausen, J. E. (1971) Acta allerg., 26, 56

CsONKA, G. (1955) WHO/VDT/136

CurTIS, J. E., and Hersh, E. M. (1973) Cell. Immunol., 8, 55

David, J. R. (1966) Proc. nat. Acad. Sci., 56, 72

-, LaWrence, H. S., and Thomas, L. (1964) $\mathcal{f}$. Immunol., 93, 279

FulfoRd, K. W. M., and Brostoff, J. (1972) Brit. f. vener. Dis., 48,483

Harris, A., Rosenberg, A. A., and Del Vecchio, E. R. (1948) F. vener. Dis. Inform., 29, 72

Hunter, E. F., Deacon, W. E., and MeYer, P. (1964) Publ. Hlth Rep. (Wash.), 79, 410

KIRALY, K. (1973) WHO/VDT/RES. 73.304

KirkPATRICK, C. H., ChandleR, J. W., and Schimke, R. N. (1970) Clin. exp. Immunol., 6, 375

LeVENE, G. M., TURK, J. L., WRIGHT, D. J. M., and Grimble, .A G. S. (1969) Lancet, 2, 246

LOWRY, O. H., Rosebrough, N. J., FARR, L., and RANDALl, R. L. (1951) f. biol. Chem., 193, 265

Magnuson, H. J., Thomas, E. V., Olansky, S., Kaplan, B. I., De Mello, L., and Cutler, J. C. (1953) Medicine (Baltimore), 35, 33

Paul, W. E., Katz, D. H., GoIld, E. A., and Benacerraf, B. (1970) f. exp. Med., 132, 283

Sapuppo, A., and Lazzaro, C. (1969) G. Derm., 44, 560

Schlossman, S. F., and Yaron, A. (1970) Ann. N.Y. Acad. Sci., 169, 108

SøвоRG, M. (1967) Acta med. scand., 182, 167 (1968) Ibid., 184, 135

TURNER, T. B. (1936) Amer. f. Hyg., 23, 431

Yoshida, T., SONOZAKI, H., and CoHEN, S. (1973) f. exp. med., 138, 784 